\title{
Effect of lonic Strength on the Performance of Dye-sensitized Solar Cells Based on Natural Dyes
}

\author{
ATEYYAH M. AL-BARADI \\ Taif University, Faculty of Science, Physics Department, Taif, Saudi Arabia. \\ ${ }^{*}$ Corresponding author E-mail: thobyani@yahoo.com \\ http://dx.doi.org/10.13005/ojc/360422
}

(Received: July 08, 2020; Accepted: August 08, 2020)

\begin{abstract}
This work is concerned with the improvement of the use of natural dyes in dye-sensitized solar cells (DSSCs). Red cabbage dye has been extracted and used to fabricate DSSCs with and without the addition of $\mathrm{NaCl}$ salt. The absorption of the extracted dye as a function of salt concentration has been investigated by spectrophotometer showing an increase of the absorption intensity with increasing the ionic strength due to the aggregation of the dye molecules. Fourier-transform infrared spectroscopy (FTIR) has been utilised to observe the bonding effect in the extracted dye upon the addition of salt. The FTIR spectra have shown a shift towards a higher wave number at the $\mathrm{O}-\mathrm{H}$ stretching vibration indicating the aggregation caused by the addition of salt ions. The photovoltaic performance of the DSSCs based on red cabbage dye as a function of salt concentration was also studied. The overall power conversion efficiency has been found to increase from $0.03 \%$ to $0.20 \%$ with increasing the salt concentration up to $5 \mathrm{M}$.
\end{abstract}

Keywords: Dye-sensitized solar cells, Natural dyes, Red cabbage, lonic strength.

\section{INTRODUCTION}

Sine last three decades, there has been an increasing attention paid to dye-sensitized solar cells (DSSCs) since its discovery by Graetzil and co-workers due to their low cost and ease of fabrication ${ }^{1-3}$. This generation of solar cells is a promising technology as a replacement of conventional solar cells especially after the reasonable achieved efficiency around $22 \%$ when highly effective materials like perovskite are used under particular conditions ${ }^{4-6}$. Although these high efficient cells are solid-state DSSCs, recent research is still currently considering the liquid electrolyte- based DSSCs ${ }^{7-11}$. A dye-sensitized solar cell consists of a porous wide-bandgap semiconductor $\left(\mathrm{TiO}_{2}\right)$ sensitized with a dye in the presence of an electrolyte. These components are sandwiched between two electrodes that made of a highly transparent conducting glass. There have been many attempts to improve the performance of each component in DSSCs ${ }^{12-15}$. The main component in DSSCs is the sensitizer (dye) that makes these cells mimicking the photosynthesis in nature, which has received a noticeable amount of research ${ }^{16-19}$. There are certain requirements that should be fulfilled for an efficient dye, such as the high absorption in the visible region, strong adsorption onto the

This is an Open Access article licensed under a Creative Commons license: Attribution 4.0 International (CC- BY). Published by Oriental Scientific Publishing Company @ 2018

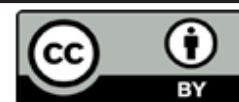


$\mathrm{TiO}_{2}$ surface, capability of injecting electrons to the conduction band of the semiconductor ${ }^{20-22}$. The best performance of DSSCs has been obtained by using Ruthenium-based dyes developed by Gratzil and co-workers including N3, N719 and black dyes $^{16,23}$. The use of such sensitizers has led to a sufficient absorption in addition to a minimum back recombination rate. However, Ru metal and their resources are very expensive and toxic materials that cannot be trusted for a wide range of applications. Therefore, natural dyes are potential alternatives with acceptable power conversion efficiency $(P C E)^{24-27}$. Such photosensitizers have many advantages over synthetic Ru-based dyes including the ease of availability, non-toxicity, the low cost of their fabricated devices and they are environmentally friendly. Over the past decade, a large number of natural dyes have been used as sensitizers to fabricate DSSCs, for example, chlorophyll, carotene ${ }^{27,28}$. These dyes can be extracted from many fruits, roses and plants leaves such as herbs, redcabbage, curcumin, red-perilla and many others ${ }^{28-30}$. The efficiency of the prepared DSSCs from these natural sensitizers varies from $0.03 \%$ to $0.7 \%$ when used as extracted. However, several structural modifications of some dyes, such as coumarin and its derivatives have led to a considerable improvement of the efficiency to $7.6 \%^{31,32}$.

In this work, a natural dye extracted from red cabbage has been treated using salt ions in order to improve the efficiency of the fabricated DSSCs. The optical properties of the prepared dye solutions with and without salt will be studied. Fourier transform infra-red (FTIR) will be utilized to explore the molecular structure of the extracted natural dye before and after the addition of salt ions. The photovoltaic properties of the prepared DSSCs will be investigated.

\section{MATERIALS AND METHODS}

Certain amounts of $\mathrm{NaCl}(0.03-1.46 \mathrm{~g})$ were dissolved in distilled water to obtain salt solutions between $0.1 \mathrm{M}$ to $5 \mathrm{M}$. Red cabbage, with a molecular structure shown in Fig. 1, was dried in a vacuum oven for five days then grinded to obtain a powder. $0.04 \mathrm{~g}$ of the red cabbage powder was dissolved in $4 \mathrm{~mL}$ of pure water and the salt solutions mentioned above. The resulting solutions were then filtered using $0.5 \mu \mathrm{m}$ filter paper. Ready-coated $\mathrm{TiO}_{2}$ films on fluorine-doped tin oxide (FTO) glass (from Solanonix) were dipped in the solutions for 12 hours. The obtained photoelectrodes with the loaded dyes were then removed and washed with acetonitrile. These photoelectrodes were used to construct dye-sensitized solar cells by placing a counter electrode (platinum coated transparent conducting oxide (TCO)) on the top of the photoelectrode, which were hold together using paper clips. The space between the front and counter electrodes was filled with a liquid electrolyte (from Solaronix) through a pinhole on the counter electrode. A 0.25 $\mathrm{cm}^{2}$ illuminated area was made on the back side of the photoelectrode by using a mask from a black tape. A photovoltaic system consisting of a solar simulator (Solar-Light) and an electrometer (Keithley 2400) was utilized to obtain the I-V characteristics of the prepared DSSCs. The system is computercontrolled to acquire and plot the I-V data after AM1.5-filtered light from the $300 \mathrm{WXenon} \mathrm{lamp} \mathrm{of} \mathrm{the}$ solar simulator shines the DSSC at a power density $\mathrm{Pi}=100 \mathrm{~mW} / \mathrm{cm}^{2}$. The absorption of the obtained dyes was investigated using a JASCO double-beam UV-Vis spectrophotometer (model V-670). Fouriertransform infrared spectroscopy (FTIR) spectra were recorded by utilizing Alpha-Attenuated FTIR spectrophotometer, Bruker, in the range of $400-4000$ $\mathrm{cm}^{-1}$ at room temperature.<smiles>Oc1cc(O)c2cc(O)c(-c3ccc(O)c(O)c3)[o+]c2c1</smiles>

Fig. 1. Molecular structure of cyanidin compound in red cappage

\section{RESULTS AND DISCUSSION}

The absorption spectra of the extracted red cabbage dye were recorded as a function of the concentration of $\mathrm{NaCl}$ using UV-Vis spectrophotometer as shown in Fig. 2. It is clear from this figure that the used dye has an absorption beak at around $550 \mathrm{~nm}$. NaCl ions have no effect on this absorption beak at all concentrations. However, the absorption intensity increases with increasing the concentration of the salt ions. This can be attributed to the aggregation of the dye molecules cased by 
the salt ions effects on the $\mathrm{OH}$ groups in the cyanidin compound in the red cabbage (see Fig. 1). A similar effect of $\mathrm{NaCl}$ salt ions was observed in previous studies $^{33}$ on organic dyes using time-resolved surface second harmonic generation (TRSSHG) technique to investigate the interfacial properties of the liquid/dye system.

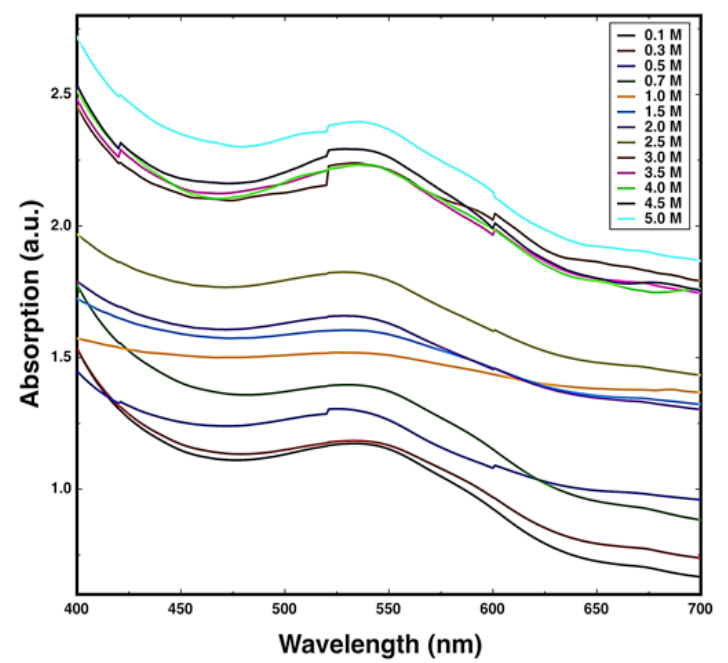

Fig. 2. Absorption spectra of red-cappage dye solutions with different concentrations of $\mathrm{NaCl}$

Figure 3 shows the FTIR spectra of the extracted red cabbage dye at different $\mathrm{NaCl}$ concentrations. The transmittance beaks in this figure between $1050 \mathrm{~cm}^{-1}$ and $1250 \mathrm{~cm}^{-1}$ are corresponding to the $\mathrm{C}-\mathrm{O}$ stretching vibrations, which are not affected by the addition of salt ions. The figure shows also transmittance beaks at $1500 \mathrm{~cm}^{-1}$ and $1700 \mathrm{~cm}^{-1}$ corresponding to $\mathrm{C}=\mathrm{C}$ and $\mathrm{C}=\mathrm{O}$ stretching vibrations, respectively, with no changes upon the addition of salt ions. The stretching vibration at $3350 \mathrm{~cm}^{-1}$ is due to the $\mathrm{O}-\mathrm{H}$ bonding. The shift towards a higher frequency in the $\mathrm{O}-\mathrm{H}$ bonding means a shorter $\mathrm{O}-\mathrm{H}$ bonding due to the electronegativity from the neighboring atoms. In addition, the transmittance decreases at this point with increasing the salt concentration, which might be attributed to the aggregation of the dye molecules. This is another evidence of the effect of the links caused by the $\mathrm{NaCl}$ ions.

Figure 4 illustrates the I-V characteristics of DSSCs based on the extracted red cabbage dye with and without the addition of $\mathrm{NaCl}$. Although the obtained efficiency from the red cabbage dye sensitized solar cells are quite low, similar to the literature ${ }^{30}$, it is clear from Fig. 4 that the performance of the DSSCs improved with increasing the concentration of the salt ions. The obtained cell parameters are listed in Table 1. The fill factor of the curves increased from 0.27 to over 0.75 indicating the worthy performance of the DSSCs upon the addition of salt ions. Table 1 shows the increase of the efficiency of the DSSCs based on red cabbage dye from $0.03 \%$ to $0.20 \%$ with increasing the salt concentration from $0 \mathrm{M}$ to $5 \mathrm{M}$. This is due to the increase of the absorption of the dye mentioned above that resulted in the increase of the photocurrent in the DSSCs with increasing the salt concentration (see Fig. 5). The sharp increase in the photocurrent in Fig. 5 as a function of salt concentration means more charge carriers are transferred to the semiconductor due to the increase of the dye aggregates in the dye/ $\mathrm{TiO}_{2}$ interface upon the addition of $\mathrm{NaCl}$. A similar aggregation effect has been observed using other organic dyes in the literature ${ }^{34}$. Fig. 6 shows the increase of the photovoltage at low concentrations of $\mathrm{NaCl}$ until a constant value of about $0.46 \mathrm{~V}$ is reached at high $\mathrm{NaCl}$ concentrations. This increase of Voc can be attributed to the help of the aggregates caused by the addition of salt ions to decrease the recombination rate in the DSSCs. The increase of the photocurrent and photovoltage upon the addition of salt resulted in a noticeable increase of the power conversion efficiency of the DSSCs based on red cabbage dye as a function of $\mathrm{NaCl}$ concentration as shown in Figure 7.

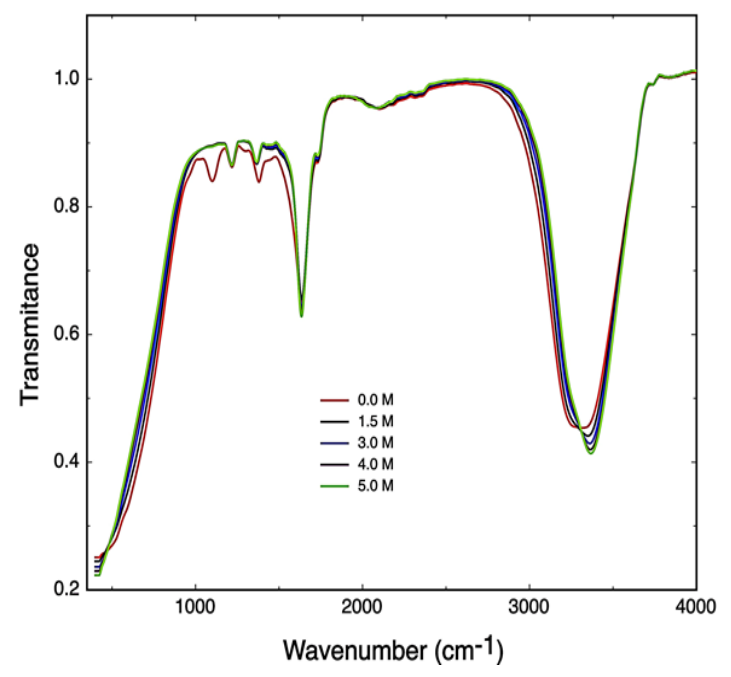

Fig. 3. FTIR spectra of red-cappage dye solutions with some selected concentrations of $\mathrm{NaCl}$ 


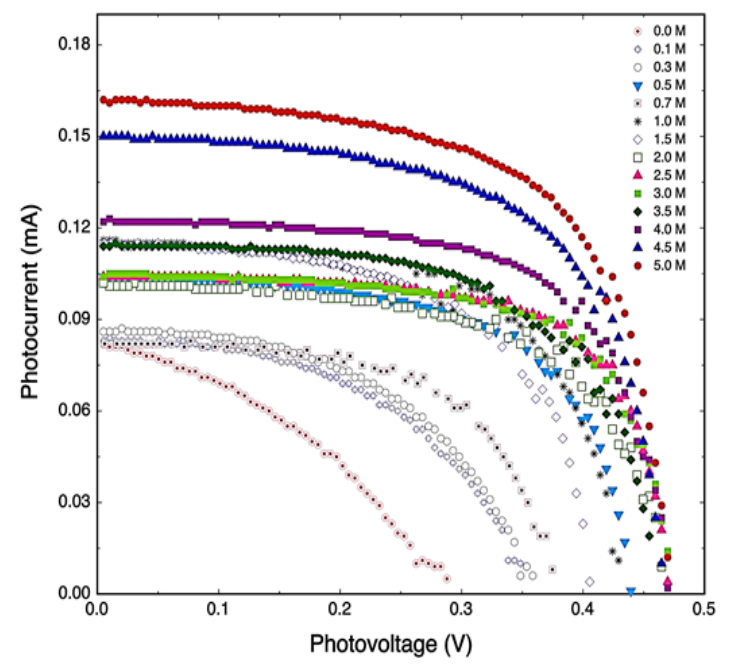

Fig. 4. I-V characteristic curves of DSSCs constructed using red-cappage dye with different concentrations of $\mathrm{NaCl}$

Table 1: I-V characteristics parameters of DSSCs prepared with a natural dye with different concentrations of salt

\begin{tabular}{cccccc}
\hline Salt conc. $(\mathrm{M})$ & $\mathrm{V}_{\text {oc }}(\mathrm{V})$ & $\mathrm{J}_{\mathrm{sc}}(\mathrm{mA})$ & $\mathrm{FF}$ & $\eta(\%)$ & $\mathrm{R}_{\text {cell }}(\Omega)$ \\
\hline 0.0 & 0.27 & 0.03 & 0.27 & 0.03 & 139 \\
0.1 & 0.35 & 0.04 & 0.41 & 0.05 & 110 \\
0.3 & 0.36 & 0.33 & 0.44 & 0.05 & 99 \\
0.5 & 0.45 & 0.40 & 0.57 & 0.10 & 89 \\
0.7 & 0.46 & 0.30 & 0.78 & 0.11 & 110 \\
1.0 & 0.45 & 0.43 & 0.57 & 0.11 & 95 \\
1.5 & 0.41 & 0.39 & 0.75 & 0.12 & 101 \\
2.0 & 0.46 & 0.36 & 0.72 & 0.12 & 87 \\
2.5 & 0.47 & 0.37 & 0.76 & 0.13 & 113 \\
3.0 & 0.47 & 0.36 & 0.78 & 0.13 & 57 \\
3.5 & 0.46 & 0.40 & 0.73 & 0.14 & 97 \\
4.0 & 0.47 & 0.43 & 0.74 & 0.15 & 103 \\
4.5 & 0.46 & 0.52 & 0.73 & 0.18 & 89 \\
5.0 & 0.46 & 0.56 & 0.75 & 0.20 & 87 \\
\hline
\end{tabular}

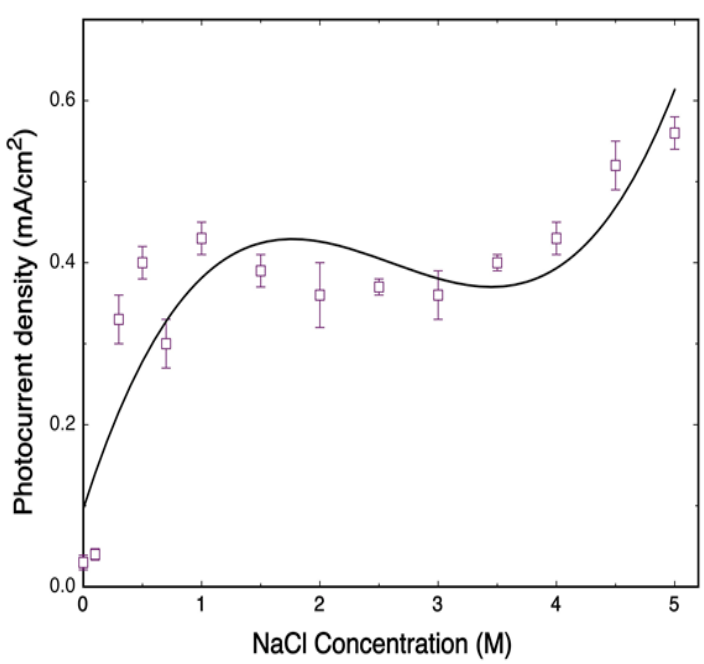

Fig. 5. Photocurrent of the constructed DSSCs using red cabbage dyes as a function of $\mathrm{NaCl}$ concentration. The solid line is a guide for the eye

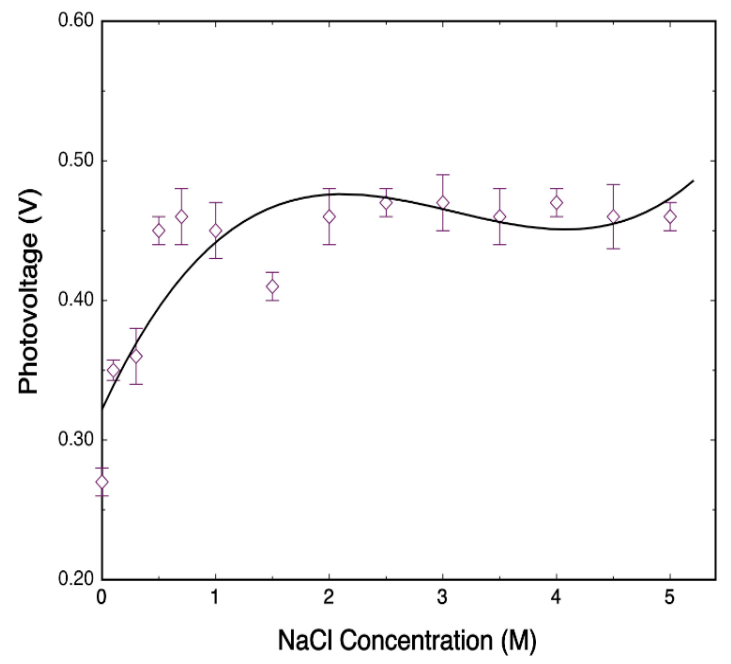

Fig. 6. Photovoltage of the constructed DSSCs using red cabbage dyes as a function of $\mathrm{NaCl}$ concentration. The solid line is a guide for the eye

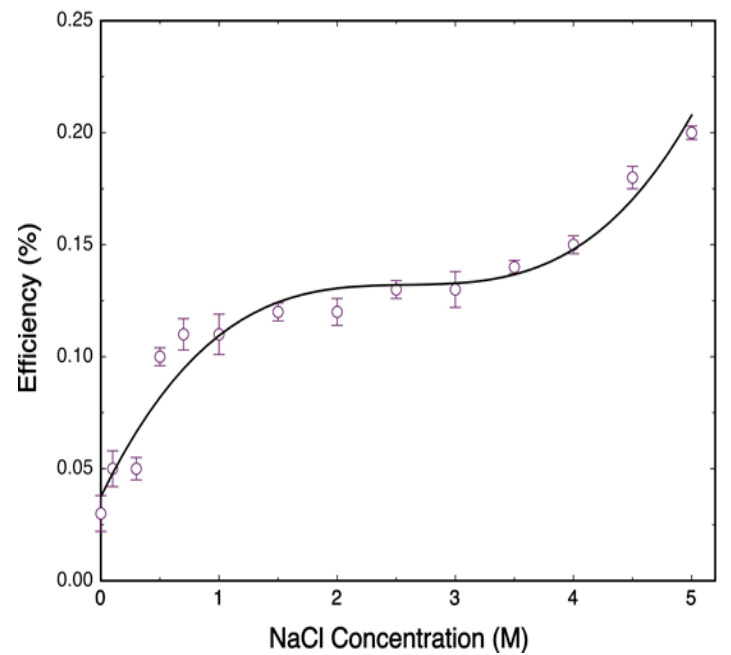

Fig. 7. Power conversion efficiency of DSSCs based on red-cappage dye as a function of $\mathrm{NaCl}$ concentration. The solid line is a guide for the eye

\section{CONCLUSION}

DSSCs have been successfully constructed based on red cabbage dye with different concentrations of $\mathrm{NaCl}$. The absorption of the red cabbage dye was measured by the spectrophotometer showing an increase with increasing the salt concentration due to the aggregation of the dye molecules. This aggregation behavior was also confirmed by the FTIR measurements that showed a shift towards a higher frequency of the peak corresponding to 
the $\mathrm{O}-\mathrm{H}$ stretching vibration. The photovoltaic performance of the DSSCs based on red cabbage dye as a function of $\mathrm{NaCl}$ was studied. A better performance was obtained with increasing the salt concentration up to $5 \mathrm{M}$ resulting in an increase of the power conversion efficiency from $0.03 \%$ to $0.20 \%$.

\section{ACKNOWLEDGEMENT}

The author thanks Dr. Ali Badawi for his support during this work.

\section{Conflicts of Interest}

The author declares no conflict of interest.

\section{REFERENCES}

1. O'regan, B.; Grätzel, M., Nature., 1991, 353, 737-740.

2. Schmidt-Mende, L.; Zakeeruddin, S. M.; Grätzel, M., Applied Physics Letters., 2005, 86, 013504.

3. Hardin, B. E.; Hoke, E. T.; Armstrong, P. B.; Yum, J.-H.; Comte, P.; Torres, T.; Fréchet, J. M.; Nazeeruddin, M. K.; Grätzel, M.; McGehee, M. D., Nature photonics., 2009, 3, 406-411.

4. Grätzel, M., Nature materials., 2014, 13, 838842.

5. Liu, Y.; Akin, S.; Pan, L.; Uchida, R.; Arora, N.; Milic, J. V.; Hinderhofer, A.; Schreiber, F.; Uhl, A. R.; Zakeeruddin, S. M., Science advances., 2019, 5, 2543.

6. Park, N.-G.; Miyasaka, T.; Grätzel, M., Cham, Switzerland: Springer., 2016.

7. AL-Baradi, A. M., Results in Physics., 2020, 103109.

8. Badawi, A.; Al-Gurashi, W. O.; Al-Baradi, A. M.; Al-Hosiny, N., Materials Science in Semiconductor Processing., 2019, 95, 1-6.

9. Maddah, H. A.; Berry, V.; Behura, S. K., Renewable and Sustainable Energy Reviews., 2020, 121, 109678.

10. Michaels, H.; Rinderle, M.; Freitag, R.; Benesperi, I.; Edvinsson, T.; Socher, R.; Gagliardi, A.; Freitag, M., Chemical Science., 2020, 11, 2895-2906.

11. Gao, N.; Huang, L.; Li, T.; Song, J.; Hu, H.; Liu, Y.; Ramakrishna, S., Journal of Applied Polymer Science., 2020, 137, 48443.

12. Gong, J.; Sumathy, K.; Qiao, Q.; Zhou, Z., Renewable and Sustainable Energy Reviews., 2017, 68, 234-246.

13. Kavan, L.; Vlckova Zivcova, Z.; Zlamalova, M.; Zakeeruddin, S. M.; Grätzel, M., The Journal of Physical Chemistry C., 2020, 124, 6512-
6521.

14. Mehmood, U.; Asghar, H.; Babar, F.; Younas, M., Solar Energy., 2020, 196, 132-136.

15. Xu, T.; Kong, D.; Tang, H.; Qin, X.; Li, X.; Gurung, A.; Kou, K.; Chen, L.; Qiao, Q.; Huang, W., ACS omega., 2020, 5, 86878696.

16. Semalti, P.; Sharma, S. N., Journal of nanoscience and nanotechnology., 2020, 20, 3647-3658.

17. Vinosha, P. A.; Ragu, R.; Kalaiarasi, S.; Xavier, B.; Das, S. J., Chemical Physics Letters., 2020, 137644.

18. Krishna, J. G.; Ojha, P. K.; Kar, S.; Roy, K.; Leszczynski, J., Nano Energy., 2020, 70, 104537.

19. Carvalho, I.; Barbosa, M.; Costa, M.; Longo, E.; Cavalcante, L.; Viana, V.; Santos, R., Optik., 2020, 165236.

20. Xiao, B.-C.; Lin, L.-Y., Nanomaterials., 2020, 10, 13.

21. Omar, A.; Ali, M. S.; Abd Rahim, N., Solar Energy., 2020, 207, 1088-1121.

22. Yang, X.; Zhao, L.; Lv, K.; Dong, B.; Wang, S., Applied Surface Science., 2019, 469, 821-828.

23. Nam, S.-H.; Lee, K. H.; Yu, J.-H.; Boo, J.-H., Applied Science and Convergence Technology., 2019, 28, 194-206.

24. Chang, H.; Kao, M.-J.; Chen, T.-L.; Kuo, C.-G.; Cho, K.-C.; Lin, X.-P., American Journal of Engineering and Applied Sciences., 2011, 4.

25. Calogero, G.; Di Marco, G., Solar Energy Materials and Solar Cells., 2008, 92, 13411346.

26. Gokilamani, N.; Muthukumarasamy, N.; Thambidurai, M.; Ranjitha, A.; Velauthapillai, D., Journal of sol-gel science and technology., 2013, 66, 212-219. 
27. Narayan, M. R., Renewable and Sustainable Energy Reviews., 2012, 16, 208-215.

28. Zhou, H.; Wu, L.; Gao, Y.; Ma, T., Journal of Photochemistry and Photobiology A: Chemistry., 2011, 219, 188-194.

29. Gómez-Ortíz, N.; Vázquez-Maldonado, I.; Pérez-Espadas, A.; Mena-Rejón, G.; Azamar-Barrios, J.; Oskam, G., Solar Energy Materials and Solar Cells., 2010, 94, 40-44.

30. Furukawa, S.; lino, H.; Iwamoto, T.; Kukita, K.; Yamauchi, S., Thin solid films., 2009, 518, 526-529.
31. Bella, F.; Sacco, A.; Pugliese, D.; Laurenti, M.; Bianco, S., Journal of Power Sources., 2014, 264, 333-343.

32. Ganta, D.; Jara, J.; Villanueva, R., Chemical physics letters., 2017, 679, 97-101.

33. Fedoseeva, M.; Fita, P.; Punzi, A.; Vauthey, E., The Journal of Physical Chemistry C., 2010, 114, 13774-13781.

34. Gao, J.; El-Zohry, A. M.; Trilaksana, H.; Gabrielsson, E.; Leandri, V.; Ellis, H.; D’Amario, L.; Safdari, M.; Gardner, J. M.; Andersson, G., ACS applied materials \& interfaces., 2018, 10, 26241-26247. 